\title{
Face Recognition using Modified Local Directional Pattern Image
}

\author{
Dong-Ju Kim ${ }^{\dagger}$ Sang-Heon Lee ${ }^{\dagger}$ Myoung-Kyu Sohn ${ }^{+}$
}

\begin{abstract}
Generally, binary pattern transforms have been used in the field of the face recognition and facial expression, since they are robust to illumination. Thus, this paper proposes an illumination-robust face recognition system combining an MLDP, which improves the texture component of the LDP, and a 2D-PCA algorithm. Unlike that binary pattern transforms such as LBP and LDP were used to extract histogram features, the proposed method directly uses the MLDP image for feature extraction by 2D-PCA. The performance evaluation of proposed method was carried out using various algorithms such as PCA, 2D-PCA and Gabor wavelets-based LBP on Yale B and CMU-PIE databases which were constructed under varying lighting condition. From the experimental results, we confirmed that the proposed method showed the best recognition accuracy.
\end{abstract}

Keywords: Face Recognition, Binary Pattern, Illumination Variation, Principal Component Analysis, Two-Dimensional Principal Component Analysis

\section{Modified Local Directional Pattern 영상을 이용한 얼굴인식}

\author{
김 동 주 $^{\dagger}$ 이 상 헌 ${ }^{\dagger} \cdot$ 손 명 $ㄱ ㅠ^{\dagger}$
}

요 약

일반적으로 이진패턴 변환은 조명 변화에 강인한 특성을 가지므로, 얼굴인식 및 표정인식 분야에 널리 사용되고 있다. 이에, 본 논문에서는 기존의 LDP(Local Directional Pattern)의 텍스처 성분을 개선한 MLDP(Modified LDP) 변환 영상에 2D-PCA(Two-Dimensional Principal Component Analysis) 알고리즘을 결합한 조명변화에 강인한 얼굴인식 방법에 대하여 제안한다. 기존의 $\mathrm{LBP}($ Local Binary Pattern)나 LDP와 같은 이진패턴 변환들이 히스토그램 특징 추출을 위해 주로 사용되는 것과는 다르게, 본 논문에서 제안하는 방법은 MLDP 영상을 $2 \mathrm{D}-\mathrm{PCA}$ 특 징추출을 위해 직접 사용한다는 특성을 갖는다. 제안 방법의 성능평가는 PCA(Principal Component Analysis), 2D-PCA 및 가버변환 영상과 $\mathrm{LBP}$ 를 결합한 알고리즘을 사용하여, 다양한 조명변화 환경에서 구축된 Yale B 및 CMU-PIE 데이터베이스를 이용하여 수행되었다. 실험 결과, MLDP 영상과 2D-PCA를 사용한 제안 방법이 가장 우수한 인식 성능을 보임을 확인하였다.

키워드 : 얼굴인식, 이진패턴, 조명변화, 주성분분석, 이차원주성분분석

\section{1. 서 론}

조명변화 환경에서의 얼굴인식은 동일한 사람이라도 다르 게 표현되므로 인식성능의 저하가 현저하게 나타나며, 따라 서 조명에 강인한 얼굴인식 방법에 대한 연구가 지속적으로 수행되고 있다[1]. 최근, 조명변화에 강인한 얼굴인식 방법 중에 하나로 가버 영상과 $\mathrm{LBP}$ 히스토그램을 이용한 방법이 있으며[2], 표정인식 분야에서는 $\mathrm{LDP}$ 변환이 소개되어 $\mathrm{LBP}$

\footnotetext{
※ 본 연구는 문화체육관광부 및 한국콘텐츠진흥원의 2013년도 문화콘텐츠산업 기술 지원사업의 연구결과와 교육과학기술부에서 지원하는 대구경북과학 기술원 기관고유사업에 의해 수행되었음(13-IT-03).

† 정 회 원 : 대구경북과학기술원 IT융합연구부 선임연구원

논문접수: 2012년 10월 5일

수 정 일 : 1 차 2012년 12 월 17 일

심사완료 : 2012년 12월 17일

* Corresponding Author:Sang-Heon Lee(pobbylee@dgist.ac.kr)
}

보다 더 강인한 이진변환 특징으로 알려져 있다[3]. 이에, 본 논문에서는 기존 $\mathrm{LDP}$ 의 텍스처 성분을 개선한 $\mathrm{MLDP}$ 영상 과 $2 \mathrm{D}-\mathrm{PCA}[4]$ 알고리즘을 결합한 얼굴인식 방법에 대하여 제안한다. 더불어, 제안 방법의 $\mathrm{MLDP}$ 변환은 기존의 이진 패턴 변환과 같이 히스토그램 특징 추출을 위해 사용되는 것이 아니라, 이진패턴 변환 영상을 $2 \mathrm{D}-\mathrm{PCA}$ 의 특징추출을 위한 입력영상으로써 직접 사용한다는 특징을 갖는다. 제안 하는 방법의 성능평가는 다양한 조명환경에서 구축한 공인 Yale B 얼굴 데이터베이스와 CMU-PIE 얼굴 데이터베이스 를 이용하여 수행되었고, 실험으로부터 제안 방법이 조명 변화에 강인한 얼굴인식 방법임을 확인하였다.

\section{2. 얼굴 영상의 전처리}

얼굴인식을 위한 $\mathrm{LBP}$ 는 그레이 레벨의 각 화소값을 이용 
하여 에지, 점, 코너 등과 같은 얼굴의 로컬 텍스처 특징을 표 현하는데 이용된다. LBP는 조명에 민감하지 않은 영상 변환 의 한 방법으로써, 인접한 각 8 개의 화소값이 중앙 화소값보 다 크면 1, 그렇지 않으면 0 의 값으로 변환하여, 총 8 비트의 패턴으로 표현하는 방법이다. $\mathrm{LBP}$ 가 영상의 그레이 레벨을 비교하여 이진패턴을 생성하는 개념을 바탕으로, 최근에는 영 상의 그레디언트 성분을 계산하고 이를 이용하여 이진패턴을 생성하는 $\mathrm{LDP}$ 와 같은 방법이 제안되었다[3]. $\mathrm{LDP}$ 는 $\mathrm{LBP}$ 보다

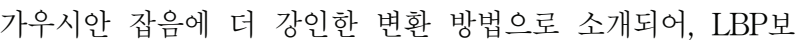
다 향상된 인식 성능을 보인다고 알려져 있다. 얼굴의 이진패 턴 변환을 위한 기존의 $\mathrm{LDP}$ 는 다음과 같은 과정으로 계산된 다[3]. 처음으로, 얼굴영상은 $3 \times 3$ 블록으로 나누어지고, 각 블록마다 Kirsch 마스크가 적용되어 에지 성분을 표현하는 그 레디언트 값 $m_{i}(i=0,1, \cdots, 7)$ 가 계산된다. 다음으로 8 개의 각 그레디언트 성분 $m_{i}$ 에 절대값을 취하고, 가장 큰 에지 응 답을 갖는 $k$ 개의 성분을 선택한다. 최종적으로, $k$ 개의 선택된 위치와 관련한 비트값 $b_{i}$ 는 1 로, 그렇지 않으면 0 의 값으로 설 정하여 Fig. 1 의 방향에 따라 8 비트의 $\mathrm{LDP}_{\mathrm{k}}$ 코드값을 생성한 다. Fig. 2는 임의의 영상블록에 대하여 $\mathrm{LDP}_{3}$ 코드를 계산하 는 과정으로, 원영상의 화소, Kirsch 마스크에 대한 에지 응답 및 최종적으로 생성된 $\mathrm{LDP}$ 코드를 보여주고 있다.

\begin{tabular}{c|c|c}
\hline$\left|m_{3}\right|$ & $\left|m_{2}\right|$ & $\left|m_{1}\right|$ \\
\hline$\left|m_{4}\right|$ & $\mathrm{X}$ & $\left|m_{0}\right|$ \\
\hline$\left|m_{5}\right|$ & $\left|m_{6}\right|$ & $\left|m_{7}\right|$ \\
\hline
\end{tabular}

(a) Edge response

Fig. 1. Edge response and LDP binary bit position

\begin{tabular}{|c|c|c|c|c|c|c|c|c|c|c|}
\hline 85 & 32 & 26 & \multirow{3}{*}{$\rightarrow$} & 313 & 97 & $|-503|$ & \multirow{3}{*}{$\rightarrow$} & 0 & 0 & 1 \\
\hline 53 & 35 & 10 & & 537 & 35 & $|-399|$ & & 1 & $\mathrm{x}$ & 1 \\
\hline 60 & 38 & 45 & & 161 & 97 & $|-303|$ & & 0 & 0 & 0 \\
\hline
\end{tabular}

Fig. 2. An example of $\mathrm{LDP}_{3}$ code

그러나, 기존 $\mathrm{LDP}$ 는 그레디언트 성분을 계산하고 가장 큰 $k$ 개의 값을 선택하는 과정에 있어, Fig. 2의 “-503”과 “-399”와 같이 음의 방향으로 큰 값을 포함하여 패턴을 구 성한다는 점과 이진패턴 생성시에 중심 화소값을 배제하는 구성한다는 단점을 갖는다. 예를 들어, 음의 방향으로 큰 값 들을 1 로 설정하여 $\mathrm{LDP}$ 패턴을 구성한다면, 결과적으로 영 상의 두드러진 그레디언트 성분을 약화시키는 효과를 갖기 때문이다. 이에 본 논문에서는 이러한 기존의 $\mathrm{LDP}$ 을 향상 시킨 $\mathrm{MLDP}$ 를 구성하였으며, 제안하는 MLDP는 Equation (1)로 표현된다.

$$
M L D P=\sum_{i=0}^{7} s\left(m_{i}-g_{c}\right) 2^{i}, \quad s(x)= \begin{cases}1 & x \geq 0 \\ 0 & x<0\end{cases}
$$

여기서, $m_{i}$ 는 주변 화소값에 대한 그레디언트 성분을 의 미하며, $g_{c}$ 는 중심 화소값을 의미한다. 즉, $\mathrm{MLDP}$ 는 중심 화 소값과 주변 화소값의 그레디언트 성분을 비교하여, 크면 1 , 그렇치 않으면 0 의 값을 설정하여 패턴을 구성한다. 더불어, 기존의 $\mathrm{LDP}$ 를 개선한 본 논문의 $\mathrm{MLDP}$ 는 임펄스 잡음에 강인한 특징을 갖는다. Fig. 3(a)와 Fig. 3(b)는 각각 임의의 영상블록과 임펄스 잡음이 존재할 경우의 이진패턴 예시를 보여주고 있다. 임펄스 잡음이 추가될 경우, 기존의 $\mathrm{LBP}$ 와 $\mathrm{LDP}$ 의 이진패턴은 서로 상이한 코드를 보이고 있으나, $\mathrm{MLDP}$ 의 이진패턴은 잡음에 상관없이 “01111100”의 동일한 패턴값을 보이고 있다. 단, Fig. 3에서 MLDP 이진패턴은 절 대값을 취하지 않은 음수의 값을 그대로 사용하여 계산된 다. 더불어, 본 논문에서 제안하는 $\mathrm{MLDP}$ 변환을 얼굴영상 에 적용한 예시가 Fig. 4에 나타나 있다. Fig. 4의 LDP 변 환영상은 음의 방향으로 큰 그레디언트 값에 절대값을 취하 여 패턴을 구성하였기 때문에, $\mathrm{LDP}$ 영상은 $\mathrm{MLDP}$ 영상보 다 얼굴의 두드러진 텍스처 성분을 더 잘 표현하지 못함을 알 수 있다.

\begin{tabular}{|c|c|c|c|c|c|c|c|}
\hline 85 & 32 & 26 & \multirow{3}{*}{$\rightarrow$} & 313 & 97 & $|-503|$ & \multirow{3}{*}{$\begin{array}{l}\text { LBP }: 11111000 \\
\text { LDP }_{3}: 00010011 \\
\text { MLDP }: 01111100\end{array}$} \\
\hline 53 & 35 & 10 & & 537 & 35 & $|-399|$ & \\
\hline 60 & 38 & 45 & & 161 & 97 & $|-303|$ & \\
\hline
\end{tabular}

(a) binary pattern values for image patch

\begin{tabular}{|c|c|c|c|c|c|c|c|}
\hline 85 & 52 & 26 & \multirow{3}{*}{$\rightarrow$} & 413 & 197 & $|-403|$ & \multirow{3}{*}{$\begin{array}{l}\text { LBP }: 11111100 \\
\text { LDP }_{3}: 00011001 \\
\text { MLDP }: 01111100\end{array}$} \\
\hline 53 & 35 & 10 & & 477 & 35 & $|-459|$ & \\
\hline 60 & 38 & 45 & & 101 & 37 & $|-363|$ & \\
\hline
\end{tabular}

(b) binary pattern values for image patch with noise Fig. 3. Stability of MLDP
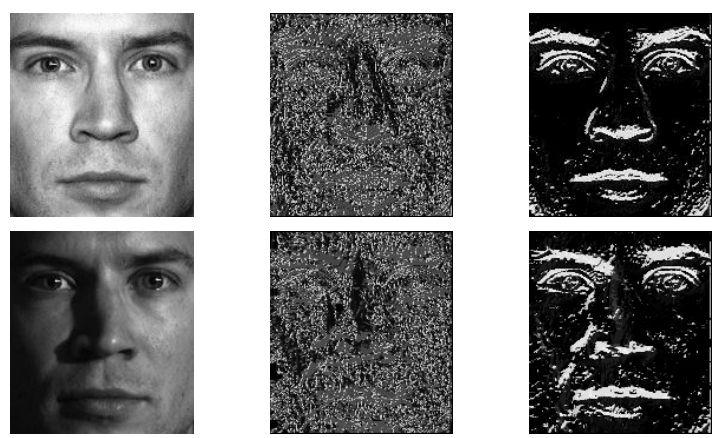

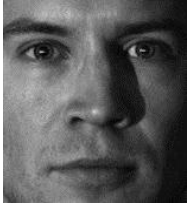

(a) Raw

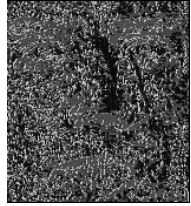

(b) $\mathrm{LDP}_{3}$
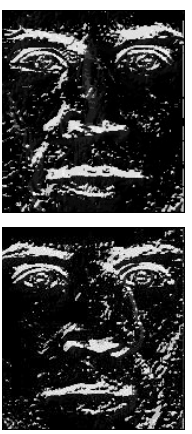

(c) MLDP
Fig. 4. Comparison of $\mathrm{LDP}_{3}$ and MLDP images 


\section{3. 얼굴 인식}

일반적으로 기존의 얼굴인식 분야에서 $\mathrm{LBP}$ 이진패턴 변 환은 변환된 영상의 각 블록에 대한 히스토그램을 추출하고, 누적된 히스토그램을 얼굴영상의 특징벡터로 이용한다[2]. 마찬가지로, 표정인식에 적용된 $\mathrm{LDP}$ 도 $3 \times 3$ 크기의 각 블 록에 대한 히스토그램을 계산하고, 이들을 하나의 벡터로 연결하여 얼굴영상의 특징으로 사용한다. 그러나 이러한 이 진패턴 영상의 히스토그램 특징은 일반적으로 벡터의 크기 가 커지게 되어, 많은 연산량을 요구한다는 단점을 갖는다. 이에 본 논문에서는 조명변화에 강인한 얼굴인식 시스템을 위하여, $\mathrm{MLDP}$ 이진패턴 변환이 수행된 얼굴영상에 직접 $2 \mathrm{D}-\mathrm{PCA}$ 를 적용하여 특징벡터를 추출하고, 이를 $\mathrm{NN}$ (Nearest Neighbor) 분류기로 인식하는 방법을 제안한다. 제 안하는 얼굴인식 접근방법은 기존의 이진패턴 변환이 히스 토그램 특징벡터를 추출하는데 이용되는 것과는 달리, 기존 의 특징벡터 추출 알고리즘의 입력영상으로 직접 사용된다 는 특징을 갖는다.

$2 \mathrm{D}-\mathrm{PCA}$ 는 $\mathrm{PCA}$ 의 공분산 행렬의 차원이 매우 커지게 되는 문제점을 극복하기 위하여, 공분산 행렬을 1 차원 벡터 로 변환하는 과정 없이 2차원 영상을 직접 사용하는 방법이 다. $2 \mathrm{D}-\mathrm{PCA}$ 는 $\mathrm{PCA}$ 보다 공분산 행렬의 크기가 매우 작으 므로 관련된 고유벡터를 계산하는데 연산량 측면에서 매우 효율적이며, $\mathrm{PCA}$ 보다 향상된 얼굴인식 성능을 보이는 것으 로 알려져 있다. 더불어, $\mathrm{PCA}$ 가 얼굴의 전역 특성을 표현하 는 특징임에 반해, $2 \mathrm{D}-\mathrm{PCA}$ 는 행 기반의 로컬 특징이므로 조명변화에 더 강인하다는 특성을 갖는다. 이에 본 논문에 서는 얼굴 특징으로써 $2 \mathrm{D}-\mathrm{PCA}$ 를 사용하였으며, $2 \mathrm{D}-\mathrm{PCA}$ 가 $\mathrm{PCA}$ 보다 조명변화에 보다 강인하다는 것을 실험으로부터 확인하였다. $2 \mathrm{D}-\mathrm{PCA}$ 는 2차원 영상을 행렬 형태로 간주하 고, 다음과 같은 과정으로 계산된다[4]. 얼굴영상 크기가 $m \times n$ 인 이미지 행렬을 $A$ 라 하고, 행들이 서로 정규직교하 는 행렬을 $X \in R^{n \times d}, n \geq d$ 라 하자. 이미지 행렬 $A$ 가 $X$ 축에 투영된다면, $m \times d$ 의 행렬은 $Y=A X$ 로 계산된다. 이때, $2 \mathrm{D}-\mathrm{PCA}$ 는 최적의 투영 행렬 $X$ 를 결정하는데, 이미 지 행렬 샘플의 분산을 사용한다. $N$ 개의 학습 영상 샘플을 $A_{k}(k=1,2, \cdot \cdot \cdot, N)$ 라 하고, 학습 샘플들의 평균이미지 를 $\bar{A}=1 / N \sum_{k} A_{k}$ 라 하자. 학습 얼굴 영상들의 이미지 공 분산 행렬 $G$ 는 Equation (2)로 계산된다.

$$
G=\frac{1}{N} \sum_{k=1}^{N}\left(A_{k}-\bar{A}\right)^{T}\left(A_{k}-\bar{A}\right)
$$

이때, 최적의 투영 행렬 $X_{o p t}$ 는 최대 고유치를 갖는 공분 산 행렬 $G$ 의 $d$ 개의 고유벡터 $X_{1}, X_{2}, \cdots \cdots, X_{d}$ 로 구성된 다. 공분산 행렬 $G$ 는 단지 $n \times n$ 의 크기를 가지므로 고유 벡터 $X_{o p t}$ 는 매우 효율적으로 계산될 수 있다. 고유벡터 $X$ 는 $n \times d$ 차원의 행렬이므로, 주어진 얼굴 영상 $A(m \times n)$ 의 특징벡터 $Y_{k}(m \times d)$ 는 Equation (3)과 같이 고유벡터의
축에 투영함으로써 계산된다. 특징추출 후, $2 \mathrm{D}-\mathrm{PCA}$ 특징 들 사이의 유클리디언 거리 기반의 $\mathrm{NN}$ 분류기에 의하여 얼 굴인식은 수행된다.

$$
Y_{k}=(A-\bar{A}) X_{k}, k=1,2, \cdots, d
$$

\section{4. 실험 및 결과}

제안하는 얼굴인식 방법의 조명 변화에 대한 효용성을 평 가하기 위하여, 본 논문에서는 Yale B 얼굴 데이터베이스와 CMU-PIE 얼굴 데이터베이스를 성능평가에 이용하였다. Yale B 얼굴 데이터베이스는 다양한 포즈와 조명 환경에서 구축된 공인 데이터베이스로써, 본 논문에서는 38 명에 대한 정면 포즈의 64 개 조명변화 환경에서 획득된 2,414장의 영상 을 실험에 사용하였다. 더불어, $\mathrm{CMU}-\mathrm{PIE}$ 얼굴 데이터베이 스는 다양한 포즈 및 조명 환경에서 68명에 대하여 구축된 데이터베이스로써, 본 논문에서는 정면 포즈의 21 개 조명 변화에 대한 1,425 개의 얼굴영상을 성능평가 실험에 사용하 였다. 성능평가에 사용한 데이터베이스의 얼굴 영역은 사용 자가 관련 얼굴영역을 지정하고, $48 \times 42$ 크기의 정규화 과 정을 거처 실험에 사용하였다. 일반적으로, Yale B 얼굴 데 이터베이스는 카메라와 조명소스와의 각도에 따라 네 개의 서브셋으로 구분할 수 있으며[5], 본 논문에서는 처음의 서 브셋을 학습 영상으로, 나머지 세 개의 서브셋을 테스트 영 상으로 사용하여 성능평가를 수행하였다. 또한 CMU-PIE 얼굴 데이터베이스의 경우, 각 개인마다 조명 변화가 거의 없는 한 장의 영상을 학습과정에 사용하였고, 나머지 20개 의 영상을 테스트 영상으로 사용하였다.

얼굴인식 성능평가는 원본영상과 히스토그램 평활화, $\mathrm{LDP}$ 및 $\mathrm{MLDP}$ 영상에 대하여 $\mathrm{PCA}$ 와 $2 \mathrm{D}-\mathrm{PCA}$ 알고리즘으로 인 식 실험을 수행하였고, 특히 원본영상과 히스토그램 평활화 영상은 성능비교를 위하여 가버영상과 $\mathrm{LBP}$ 를 이용한 얼굴인 식 실험에 추가적으로 이용되었다. 실험결과, Yale B 데이터 베이스를 이용한 특징차원에 따른 얼굴인식 실험결과를 Fig. 5 에 나타내었으며, CMU-PIE 데이터베이스를 사용한 경우의 실험 결과를 Fig. 6에 나타내었다. 더불어, 실험을 바탕으로 Table 1과 Table 2에 각 데이터베이스에 대한 성능평가 결 과를 요약하였다. 또한, 기존방법과의 성능비교를 위하여, 본 논문에서는 가버영상에 $\mathrm{LBP}$ 를 적용하고 히스토그램을 특징 벡터로 사용하는 얼굴인식 방법에 대한 실험 결과를 추가적 으로 나타내었다. 실험으로부터 제안하는 $\mathrm{MLDP}$ 와 2D-PCA 를 결합한 얼굴인식 방법은 Yale $\mathrm{B}$ 데이터베이스의 경우 $96.14 \%, \mathrm{CMU}-\mathrm{PIE}$ 데이터베이스의 경우에는 $100.0 \%$ 의 인식 률을 보였다. 반면, $\mathrm{LDP}$ 영상과 $2 \mathrm{D}-\mathrm{PCA}$ 를 결합한 실험 결 과는 기존의 가버영상과 $\mathrm{LBP}$ 를 이용한 방법보다 더 낮은 성 능을 보였으며, 전체적으로 $\mathrm{PCA} ㅂ ㅗ ㄷ ㅏ ~ 2 \mathrm{D}-\mathrm{PCA}$ 의 경우에 전 체적으로 더 나은 성능을 보였다. 실험 결과로부터, 본 논문 에서는 제안하는 얼굴인식 방법이 조명변화에 강인한 효과적 인 얼굴 인식 방법임을 확인하였다. 


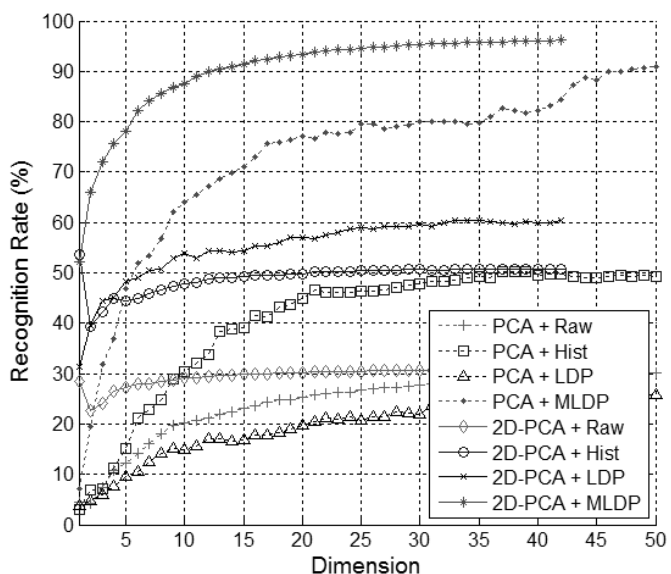

Fig. 5. Recognition results for the Yale B database

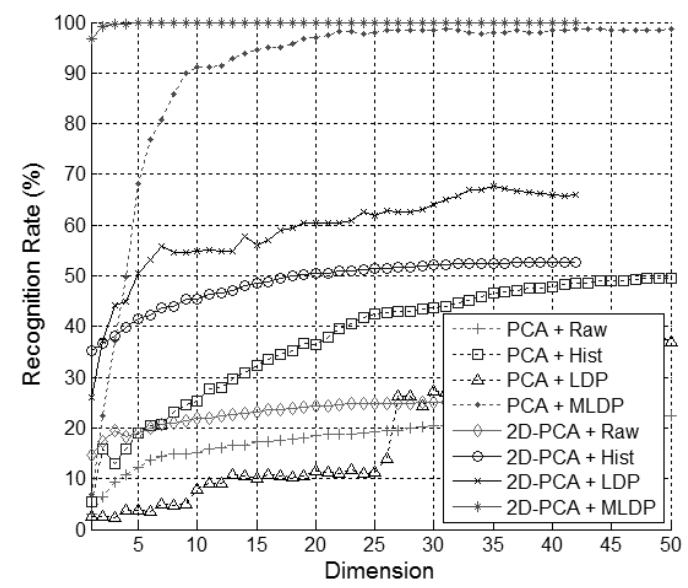

Fig. 6. Recognition results for the CMU-PIE database

Table 1. Maximum recognition rates for the Yale B database

\begin{tabular}{cccc}
\hline & \multicolumn{3}{c}{ Recognition Approaches } \\
\cline { 2 - 4 } & PCA & 2D-PCA & Gabor+LBP \\
Raw & $30.17 \%$ & $30.78 \%$ & $57.14 \%$ \\
Histogram & $49.72 \%$ & $50.79 \%$ & $69.50 \%$ \\
LDP $_{3}$ & $27.40 \%$ & $60.52 \%$ & $\mathrm{X}$ \\
MLDP & $90.93 \%$ & $96.14 \%$ & $\mathrm{X}$ \\
\hline \hline
\end{tabular}

Table 2. Maximum recognition rates for the CMU-PIE database

\begin{tabular}{cccc}
\hline & \multicolumn{3}{c}{ Recognition Approaches } \\
\cline { 2 - 4 } & $\mathrm{PCA}$ & $2 \mathrm{D}-\mathrm{PCA}$ & Gabor+LBP \\
Raw & $22.35 \%$ & $25.22 \%$ & $63.23 \%$ \\
Histogram & $49.63 \%$ & $52.72 \%$ & $82.20 \%$ \\
$\mathrm{LDP}_{3}$ & $36.91 \%$ & $67.64 \%$ & $\mathrm{X}$ \\
MLDP & $98.75 \%$ & $100.0 \%$ & $\mathrm{X}$ \\
\hline
\end{tabular}

\section{5. 결 론}

본 논문에서는 조명에 강인한 얼굴인식을 위하여 $\mathrm{MLDP}$ 변환 영상에 $2 \mathrm{D}-\mathrm{PCA}$ 를 직접 적용하는 방법에 대하여 제안 하였다. 제안 방법의 성능평가는 조명 변화 환경에서 구축
된 Yale B 및 CMU-PIE 데이터베이스를 사용하여 수행되 었고, 실험결과, $\mathrm{MLDP}$ 영상에 $2 \mathrm{D}-\mathrm{PCA}$ 를 적용한 제안 방 법이 가장 우수한 성능을 보임을 확인하였다.

\section{참 고 문 헌}

[1] N.B. Kachare and V.S. Inamdar, "Survey of face recognition techniques," Int. Conf. Computer Applications, Vol.1, No.1, pp.29-33, 2010.

[2] H. Di, S. Caifeng, M. Ardabilian, W. Yunhong, C. Liming, Local Binary Patterns and Its Application to Facial Image Analysis: A Survey, IEEE Transactions on Systems, Man, and Cybernetics, Part C, Vol.41, No.6, pp.765-781, 2011.

[3] T. Jabid, M.H. Kabir, and O. Chae, "Robust Facial Expression Recognition based on Local Directional Pattern," ETRI J., Vol.32, No.5, pp.784-794, 2010.

[4] Y. Jian, Z. David, F. Alejandro, and J. Y. Yang, "Twodimensional PCA: A new approach to appearance-based face representation and recognition," IEEE Trans. Pattern Anal. Mach. Intell., Vol.26, No.1, pp.131-137, 2004.

[5] A. Georghiades, P. Belhumeur, and D. Kriegman, "From few to many: Illumination Cone Models for Face Recognition under Variable Lighting and Pose," IEEE Trans. Pattern Anal. Mach. Intell., Vol.23, No.6, pp.643-660, 2001.

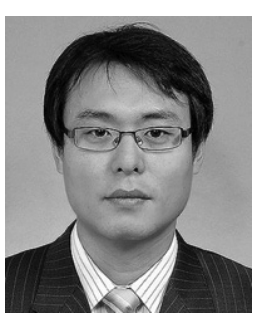

\section{김 동 주}

e-mail : radioguy@dgist.ac.kr 1998년 충북대학교 전파공학과(학사) 2000년 충북대학교 전파공학과(석사) 2010년 성균관대학교 정보통신공학부(박사) 2011년 현 재 대구경북과학기술원 IT융합연구부 선임연구원 관심분야: 얼굴인식, $\mathrm{HCI}$, 영상신호처리, 패턴인식

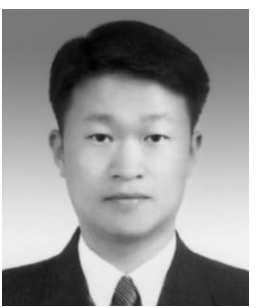

이 상 헌

e-mail : pobbylee@dgist.ac.kr 1993년 경북대학교 전자공학과(학사) 1996년 경북대학교 전자공학과(석사) 2009년 경북대학교 전기전자공학과(박사) 2005년 현 재 대구경북과학기술원 IT융합연구부 선임연구원 관심분야: 컴퓨터비전, 영상신호처리

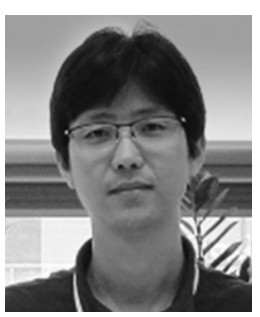

손 명 규 e-mail :smk@dgist.ac.kr 1997년 경북대학교 전자공학과(학사) 1999년 서울대학교 전기공학과(석사) 2005년 현 재 대구경북과학기술원

IT융합연구부 선임연구원 관심분야: $\mathrm{HCI}$, 패턴인식, 컴퓨터비전 